\title{
Erros de administração de medicação em pediatria
}

\author{
Karynne Borges Cabral*, Pâmela Roberta de Oliveira**, Patrícia Freire Cavalcante, M.Sc.***
}

*Enfermagem em neonatologia e pediatria do CEEN - PUC/GO, Enfermeira da Unidade de Pronto Atendimento de Rio Verde$G O,{ }^{* *}$ Especialista em vigilância alimentar e nutricional para saúde indígena pela Fiocruz-RJ, Mestranda em Educação pela UFMT-MT, Professora auxiliar do curso de enfermagem da UFMT-Campus Universitário, ***Docente do CEEN-PUC/GO

\section{Resumo}

Objetivo: Analisar os erros mais comuns de administração de medicações nos clientes pediátricos, segundo revisão da literatura brasileira. Material e métodos: Estudo de revisão bibliográfica de caráter descritivo analítico com abordagem qualitativa. Foram utilizados como objeto de estudo um total de onze artigos, originados de bases de dados Bireme e Scielo e periódico científico impresso, os quais foram selecionados a partir dos descritores: pediatria, enfermagem, erros de medicaçáo. Resultados: Um total de 183 artigos foi encontrado, no entanto apenas onze foram selecionados para compor este estudo. Após leitura e tratamento dos artigos, percebeu-se que entre os erros mais comuns de administração de medicamentos estão os erros de prescrição, dispensação, omissão de horário, de dose, de apresentação, de preparo, devido a técnicas incorretas na administração etc. As causas se relacionam ao sistema de medicação que engloba desde o momento da prescrição até a administração propriamente dita. Quanto à prevençáo de erros, a literatura sugere entre outras medidas o treinamento periódico da equipe, gerenciamento dos riscos e outros. Conclusão: É importante que novas pesquisas sejam realizadas, principalmente em campo, para que as instituiçóes de saúde possam identificar os erros particulares de seu próprio sistema e, entấo, seja capaz de elaborar medidas próprias para minimizá-los de acordo com sua realidade particular.

Palavras-chave: pediatria, enfermagem, erros de medicação.

\section{Abstract \\ Medication administration errors in children}

Objective: To analyze the most common medication administration errors in children, according to Brazilian literature review. Material and methods: This literature review was conducted by applying analytical descriptive method with qualitative approach. A total of eleven articles from Bireme and Scielo databases and other scientific publications were selected, using the following descriptors: pediatrics, nursing, medication errors. Results: We found 183 articles, however only eleven were included in this study. After reading and processing of articles, we noticed that the most common errors in medication administration occur in the prescribing, dispensing, dose omission, wrong time, wrong dose preparation, due to incorrect administration techniques, etc. The medication errors are related to the medication system which includes the time of prescription until 
the medication is administered. Concerning prevention of medical errors, the literature suggests among other measures the periodic training for all staff, risk management and others. Conclusion: We need future researches, especially field research, so that health institutions may identify particular errors of their own system and able to develop their own measures to minimize them according to their reality.

Key-words: pediatrics, nursing, medication errors.

\section{Resumen}

\section{Errores en la administración de medicamentos en pediatría}

Objetivo: Analizar los errores más frecuentes en la administración de medicamentos en niños, según revisión de la literatura brasileńa. Materiales y métodos: Se trata de una revisión de la literatura de carácter descriptivo analítico con enfoque cualitativo. Se han utilizado como objeto de estudio un total de once artículos, procedentes de bases de datos de Bireme y Scielo, y publicación periódica científica, que fueron seleccionados a partir de los descriptores: pediatría, enfermería, errores de medicación. Resultados: Se encontraron un total de 183 artículos de los cuales sólo once fueron seleccionados para la realización de este estudio. Después de la lectura y procesamiento de los artículos, se observó que entre los errores más frecuentes de administración de medicamentos están errores en la prescripción, dispensación, omisión del horario, dosis, presentación, preparación, debido a las técnicas incorrectas en el manejo, etc. Las causas están relacionadas con el sistema de medicación que incluye el tiempo desde la prescripción del medicamento a la administración. Con relación a la prevención de errores en la medicación, la literatura sugiere, entre otras medidas, el entrenamiento del equipo de enfermería, gestión de riesgos y otros. Conclusión: Es importante que se realicen más investigaciones, especialmente las de campo, para que las instituciones de salud puedan identificar los errores de su propio sistema y que puedan desarrollar medidas para reducirlos al mínimo de acuerdo a su realidad.

Palabras-clave: pediatría, enfermería, errores de medicación.

\section{Introdução}

Entende-se que o medicamento é qualquer agente químico que, ao ser administrado no organismo vivo, é capaz de produzir algum efeito benéfico [1].

A administração de medicação constitui o ato de preparo e introduçáo de um fármaco no organismo humano, com uma finalidade terapêutica [2]. Embora esta seja uma atividade da equipe de enfermagem praticada há muitos anos, ainda nos deparamos com erros durante esses procedimentos que podem ser fatais, principalmente na população pediátrica.

A Agência Nacional de Vigilância Sanitária (ANVISA) define como erro de medicação "qualquer evento evitável que, de fato, ou potencialmente, pode levar ao uso inadequado de medicamento", podendo ou náo causar dano ao paciente, seja esta medicaçáo em poder e controle de pacientes, familiares ou profissionais de saúde [3].

Observa-se que, na maioria dos países, os três grupos de medicamentos mais utilizados em crianças são antibióticos, analgésicos, antitérmicos e medicamentos de ação no aparelho respiratório, sendo que muitos deles são utilizados de forma inadequada [4].
O procedimento de administraçáo de medicamentos em pediatria náo difere do realizado em adultos, porém deve-se considerar que não existem disponíveis no mercado medicamentos com apresentaçôes e dosagens específicas para crianças [2], o que certamente contribui de forma significativa para a ocorrência de erros relacionados à administração de fármacos a essa clientela.

Recentemente, no Brasil, foi noticiado, com grande repercussão na mídia de nosso país, um caso de óbito de uma criança em que teve vaselina administrada por via endovenosa ao invés de soro fisiológico. Isso nos leva a questionar e refletir, como uma profissão tão antiga e um procedimento realizado por diversas vezes e em um mesmo período de trabalho consegue cometer erros táo fatais.

Diante do exposto acima, surge a questão central: Quais são os erros mais frequentes relacionados à administraçáo de medicação em clientes pediátricos, segundo revisão da literatura brasileira?

Assim este estudo justifica-se pela importância de se abordar os erros mais comuns relacionados à administração de medicação em clientes pediátricos e também os fatores relacionados a estes erros, a fim de elaborar medidas para evitá-los. Justifica-se ainda 
pela necessidade de conhecer melhor uma realidade negativa que tem sido frequente na rotina de enfermagem em todo o nosso país, propiciando ao enfermeiro subsídios para implementar estratégias de educação permanente visando a minimização destes eventos.

\section{Objetivo}

Analisar os erros mais comuns de administração de medicação em clientes pediátricos, segundo revisão da literatura brasileira.

\section{Material e métodos}

\section{Amostragem e critérios de inclusão}

Foram utilizados como objeto de estudo artigos científicos de base de dados virtuais - Bireme, Scielo e revistas científicas.

O período de busca iniciou-se no mês de janeiro de 2011 e findou em março do mesmo ano, seguido do período de leitura e agrupamento dos dados encontrados que ocorreu de abril a junho de 2011.

Nas bases de dados Bireme e Scielo foram encontrados 182 artigos, publicados entre 2003 e 2010, utilizando como descritores as palavras pediatria, enfermagem, erros e medicação, dos quais foram selecionados apenas 10 artigos. Em relação à pesquisa sistemática em periódico científico impresso, foi selecionado 1 artigo (Revista Enfermagem Brasil). Dessa forma, foram incluídos nesta pesquisa, um total de 11 artigos.
Como critérios de exclusão: artigos não relacionados com o tema e aqueles com data de publicação anterior ao ano de 2000 e ainda aqueles com publicaçóes referentes à realidade estrangeira.

Trata-se de uma revisão bibliográfica de caráter descritivo explicativo e com uma abordagem qualitativa.

Desta forma o presente estudo envolveu a leitura dos artigos, de modo que requereu uma abordagem que privilegiasse a compreensão do fenômeno estudado. Portanto, a análise documental foi utilizada como técnica principal de apreensão de dados.

O processo de análise de dados do trabalho seguiu padronização utilizada em análise qualitativa [5,6] nas seguintes etapas: a) Leitura dos artigos; b) Coleta de dados; c) Categorias (Reincidência e relevância); d) Revisão de categorias; e) Seleção de autores de âncoras; f) Interpretação do sistema de categorias.

Uma vez estabelecidas, as categorias foram revistas e cada uma delas recebeu um nome e um número de código. Em seguida, selecionaram-se outros materiais (livros, artigos, teses, dissertaçôes e outros) sobre o tema, chamados de âncora - segmentos de texto específicos relacionados com uma dada categoria e que servem de exemplo para ela [7]. A etapa final consistiu na interpretação do sistema de categorias, em termos das questóes da pesquisa e do quadro referencial teórico.

Tendo em vista o objetivo do presente trabalho, foram selecionadas as seguintes categorias: a) Erros de administração de medicação em pediatria; b) Fatores de risco ou causas associadas; c) Prevenção dos erros de administração de medicamentos.

\section{Resultados e Discussão}

Quadro I - Demonstrativo do fluxo da análise dos artigos.

\begin{tabular}{|l|l|l|l|l|}
\hline $\begin{array}{c}\text { Base - } \\
\text { Origem }\end{array}$ & \multicolumn{1}{|c|}{ Título do artigo } & \multicolumn{1}{c|}{ Autores } & Periódico-Revista & \multicolumn{1}{c|}{ Considerações/ Temática } \\
\hline Scielo & $\begin{array}{l}\text { Revelação da } \\
\text { ocorrência de erros } \\
\text { de medicação em } \\
\text { unidade de cuidados } \\
\text { intensivos pediátri- } \\
\text { cos. }\end{array}$ & $\begin{array}{l}\text { Belena ASC et al. } \\
{[8]}\end{array}$ & $\begin{array}{l}\text { Revista Brasileira } \\
\text { de terapia inten- } \\
\text { siva }\end{array}$ & $\begin{array}{l}\text { Estudo descritivo exploratório. Des- } \\
\text { creve a ocorrência da comunicação } \\
\text { de erro de medicação à equipe e a } \\
\text { família em uma unidade de cuidados } \\
\text { intensivos pediátricos para atendimen- } \\
\text { to de pacientes oncológicos. }\end{array}$ \\
\hline
\end{tabular}




\begin{tabular}{|c|c|c|c|c|}
\hline Bireme & $\begin{array}{l}\text { Avaliação dos fatores } \\
\text { de risco relacionados } \\
\text { às falhas durante a } \\
\text { administração de } \\
\text { medicamentos. }\end{array}$ & $\begin{array}{l}\text { Freitas DF, Oda } \\
\text { JY [9] }\end{array}$ & $\begin{array}{l}\text { Arquivo de Ci- } \\
\text { ências da Saúde } \\
\text { - Unopar }\end{array}$ & $\begin{array}{l}\text { Pesquisa de campo com aplicação } \\
\text { de questionário objetivo, buscando } \\
\text { identificar o conhecimento da equipe } \\
\text { de enfermagem sobre o preparo e } \\
\text { administração de medicamentos, } \\
\text { as intercorrências mais frequentes, } \\
\text { intervenções tomadas frente ao erro } \\
\text { e eventuais sugestões para a preven- } \\
\text { ção de falhas durante o processo da } \\
\text { terapia medicamentosa. }\end{array}$ \\
\hline Scielo & $\begin{array}{l}\text { Tecnologia da infor- } \\
\text { mação e prevenção } \\
\text { de erros de medi- } \\
\text { cação em pediatria: } \\
\text { prescrição informa- } \\
\text { tizada, código de } \\
\text { barras e bombas de } \\
\text { infusão inteligentes. }\end{array}$ & $\begin{array}{l}\text { Pedreira ML G et } \\
\text { al. [10] }\end{array}$ & $\begin{array}{l}\text { Revista Sociedade } \\
\text { Brasileira de Enfer- } \\
\text { magem Pediátrica }\end{array}$ & $\begin{array}{l}\text { Descreve a importância da tecnologia } \\
\text { da informação na prevenção de erros } \\
\text { de medicação em pediatria. }\end{array}$ \\
\hline Scielo & $\begin{array}{l}\text { Carência de prepa- } \\
\text { rações medicamen- } \\
\text { tosas para uso em } \\
\text { crianças no Brasil. }\end{array}$ & $\begin{array}{l}\text { Costa PQ et al. } \\
{\left[\begin{array}{ll}1 & 1\end{array}\right]}\end{array}$ & Jornal de Pediatria & $\begin{array}{l}\text { Estudo descritivo que busca identificar } \\
\text { medicamentos que apresentam difi- } \\
\text { culdades para seu uso no Brasil. }\end{array}$ \\
\hline Scielo & $\begin{array}{l}\text { Erros de medicação } \\
\text { em hospital univer- } \\
\text { sitário: tipo, causas, } \\
\text { sugestões e provi- } \\
\text { dências. }\end{array}$ & $\begin{array}{l}\text { Silva AEBC, Cas- } \\
\text { siani SHB [12] }\end{array}$ & $\begin{array}{l}\text { Revista Brasileira } \\
\text { de Enfermagem }\end{array}$ & $\begin{array}{l}\text { Estudo survey exploratório que ana- } \\
\text { lisou os erros de medicação de um } \\
\text { hospital universitário a partir de } 40 \\
\text { entrevistas com profissionais do siste- } \\
\text { ma de medicação. }\end{array}$ \\
\hline Scielo & $\begin{array}{l}\text { Estratégias para pre- } \\
\text { venção de erros na } \\
\text { medicação no setor } \\
\text { de emergência. }\end{array}$ & $\begin{array}{l}\text { Oliveira RC et al. } \\
\text { [13] }\end{array}$ & $\begin{array}{l}\text { Revista Brasileira } \\
\text { de Enfermagem }\end{array}$ & $\begin{array}{l}\text { Estudo que identificou as situações } \\
\text { indicativas de erro ou quase erro na } \\
\text { medicação através da análise das } \\
\text { prescrições de medicamentos e evolu- } \\
\text { ções de enfermagem. }\end{array}$ \\
\hline Scielo & $\begin{array}{l}\text { Uso judicioso de } \\
\text { medicamentos em } \\
\text { crianças. }\end{array}$ & Bricks LF [4] & Jornal de Pediatria & $\begin{array}{l}\text { Estudo de revisão bibliográfica sobre } \\
\text { o uso criterioso de medicamentos em } \\
\text { crianças. }\end{array}$ \\
\hline Bireme & $\begin{array}{l}\text { Redesenho das ativi- } \\
\text { dades de enferma- } \\
\text { gem para redução } \\
\text { de erros de medica- } \\
\text { ção em pediatria. }\end{array}$ & $\begin{array}{l}\text { Yamanaka } \mathrm{T} \text { I et } \\
\text { al. [14] }\end{array}$ & $\begin{array}{l}\text { Revista Brasileira } \\
\text { de Enfermagem }\end{array}$ & $\begin{array}{l}\text { Estudo quase-experimental que } \\
\text { verificou a influência do redesenho de } \\
\text { atividades de enfermagem para a re- } \\
\text { dução de erros de medicação em três } \\
\text { unidades de pediatria de um hospital } \\
\text { universitário. }\end{array}$ \\
\hline Bireme & $\begin{array}{l}\text { Erros de medicação } \\
\text { em pediatria: análise } \\
\text { da documentação } \\
\text { de enfermagem } \\
\text { no prontuário do } \\
\text { paciente. }\end{array}$ & $\begin{array}{l}\text { Melo LR, Pedreira } \\
\text { MLG [15] }\end{array}$ & $\begin{array}{l}\text { Revista Brasileira } \\
\text { de Enfermagem }\end{array}$ & $\begin{array}{l}\text { Estudo descritivo e transversal reali- } \\
\text { zado em três unidades pediátricas de } \\
\text { um hospital universitário que objeti- } \\
\text { vou, por meio da análise do prontu- } \\
\text { ário do paciente, identificar erros de } \\
\text { medicação. }\end{array}$ \\
\hline
\end{tabular}




\begin{tabular}{|l|l|l|l|l|}
\hline Bireme & $\begin{array}{l}\text { Erros de medicação: } \\
\text { condutas e propostas } \\
\text { de prevenção na } \\
\text { perspectiva da equi- } \\
\text { pe de enfermagem. }\end{array}$ & Silva BK et al. [17] & $\begin{array}{l}\text { Revista Eletrônica } \\
\text { de Enfermagem }\end{array}$ & $\begin{array}{l}\text { Estudo transversal, descritivo e explo- } \\
\text { ratório que identificou por meio de } \\
\text { relatos da equipe de enfermagem, } \\
\text { condutas do enfermeiro frente aos er- } \\
\text { ros na medicação e as ações propos- } \\
\text { tas para minimizar tais erros. }\end{array}$ \\
\hline $\begin{array}{l}\text { Periódico } \\
\text { científico }\end{array}$ & $\begin{array}{l}\text { Avaliação do conhe- } \\
\text { cimento da equipe } \\
\text { de enfermagem em } \\
\text { relação à diluição de } \\
\text { antibióticos utilizados } \\
\text { no tratamento de } \\
\text { pneumonia aguda } \\
\text { em pacientes pediá- } \\
\text { tricos. }\end{array}$ & $\begin{array}{l}\text { Bueno A, Suyenga } \\
\text { ES [1] }\end{array}$ & $\begin{array}{l}\text { Revista Enferma- } \\
\text { gem Brasil }\end{array}$ & $\begin{array}{l}\text { Estudo transversal, com abordagem } \\
\text { quantitativa, para verificar o conheci- } \\
\text { mento da equipe de enfermagem na } \\
\text { diluição de antibióticos utilizados no } \\
\text { tratamento de pneumonia aguda de } \\
\text { pacientes pediátricos. }\end{array}$ \\
\hline
\end{tabular}

\section{Erros de administraçáo de medicaçáo em pediatria}

Após leitura dos artigos selecionados, foi possível perceber que erros relacionados à assistência à saúde, ocorrem com certa frequência, refletindo a complexidade do sistema aliada à natureza humana capaz de cometer erros [8].

Para alguns autores os erros de medicação aparecem como a principal categoria isolada de erros presentes no sistema de assistência à saúde [10].

Os artigos estimam que aproximadamente 3\% dos pacientes internados em unidades hospitalares desenvolvem algum tipo de efeito adverso grave, durante o uso de medicamentos. O risco da ocorrência de erros em adultos e crianças é semelhante, embora o potencial desses erros causarem danos aos pacientes pediátricos chega a ser três vezes maior [8].

Um estudo realizado em três unidades de um hospital universitário mostrou que a ocorrência de erros antes e após uma intervenção foi mais frequente na unidade de infectologia pediátrica, seguida da cirurgia pediátrica e por último na unidade de cuidados intensivos pediátricos [14].

Os autores pesquisados consideram erros como "sintomas de sistemas doentes", que são causados por falhas do sistema e náo por falhas das pessoas. Afirmam ainda que para reduzi-los deve-se focar no sistema [15].

Assim definem o erro como "o uso, não intencional de um plano errado para alcançar um objetivo, ou a náo execução a contento de uma ação planejada” [10].

Erros de medicaçóes são considerados por alguns autores como eventos adversos do medi- camento, previsíveis, possíveis de ocorrer em uma ou em várias etapas dentro do procedimento de administração, desde o momento da prescrição até sua administração propriamente dita [12].

Um evento adverso é caracterizado pela presença do dano em consequência de um erro, que pode ser evitado, sendo definido como um prejuízo com lesão permanente ou temporária, em decorrência do uso incorreto de um fármaco, mesmo que esse erro seja devido à falta do medicamento na instituição [8].

Segundo os autores pesquisados, em nosso cotidiano de trabalho, os erros sempre recaem à equipe de enfermagem e isso ocorre devido à enfermagem ser o elo final do processo de administraçáo de medicamentos, sendo seus atos marcados pela transição de um erro previsível para um erro real. Portanto a enfermagem constitui a última "oportunidade de interceptar o erro de medicação" [15].

É importante entender que todo erro resulta em algum tipo de dano. Aqueles capazes de causar lesôes ou prejuízos são considerados eventos adversos, "agravos decorrentes de intervençóes realizadas por profissionais de saúde" e que não estão relacionados às condiçóes próprias dos pacientes. Ressaltamos ainda que "nem todos os eventos adversos são relacionados aos erros" [14].

Entre os tipos de erros relacionados à medicação, encontrados na literatura analisada, podemos citar erros de prescrição; erro de dispensação; erro de omissão; erro de horário; erro de administração de medicamento não autorizado; erro de dose; erro de apresentação; erro de preparo; erro de administração; erros com medicamentos deteriorados; erros 
de monitoração; erro em razão da não aderência do paciente e família; entre outros [8].

Além dos erros citados acima, outros autores consideram ainda: a dose extra; erros de via e erros devido a técnicas incorretas na administração [13].

Pode-se considerar ainda a troca do paciente, a troca de medicaçáo e o controle inadequado de gotejamentos de soluçóes endovenosas como erros relacionados à administração de fármacos [13].

$\mathrm{O}$ erro de dose se caracteriza pela administração de uma dose menor ou maior que a prescrita para o paciente, ou ainda a administraçáo de doses duplicadas ao mesmo [10]. Neste último caso as falhas nas anotaçóes de enfermagem, em especial a náo checagem de uma dose administrada contribui de forma significativa para sua ocorrência. No entanto náo devemos considerar erros de dose os casos em que esta se determina pela reação orgânica do paciente como, por exemplo, a insulina, antiémeticos, antitérmicos e outros [10].

Um estudo realizado em três unidades pediátricas mostrou que os erros de omissão corresponderam à maioria dos erros encontrados representando $75,7 \%$ dos erros avaliados [15].

O erro de omissão é aquele que ocorre em decorrência da não administraçáo de uma dose prescrita para o paciente. Ressaltamos que não se caracteriza como erro, os casos em que o paciente recusa uma medicação ou quando há uma contraindicaçáo reconhecida [8].

Profissionais participantes de um estudo realizado em um hospital geral universitário relataram que os erros de medicação são mais frequentes no momento da prescriçáo de medicamentos e estão relacionados à sua legibilidade e a medicamentos prescritos de forma inadequada [12].

Erros de prescrição de medicamentos estáo relacionados à seleção incorreta do medicamento que inclui a indicação, a contraindicação, as alergias desconhecidas do paciente e a existência de certas terapias medicamentosas, além da dose, velocidade de infusão, prescrição ilegível e instruções incorretas quanto ao uso do medicamento capaz de induzir ao erro [10].

Os erros de medicação em pediatria apresentam maior incidência na fase da prescriçáo. Segundo os autores, isso ocorre devido à necessidade de realização de cálculos decimais e do uso de doses fracionadas para sua administração [10].

Um estudo revelou que 17 (32\%) dos participantes haviam administrado medicação ao paciente errado por pelo menos cinco vezes e $1(2 \%)$ havia cometido o mesmo erro por mais de cinco vezes; 13 (24\%) já tinham diluído medicação de forma errada por pelo menos cinco vezes e $1(2 \%)$ relatou que a diluição errada ocorre com frequência; 7 (13\%) já tinham administrado medicação por via errada, por pelo menos cinco vezes e 2 (4\%) tinham administrado medicação errada ao paciente [9].

O sistema de administração de fármacos nas instituiçóes hospitalares envolve diversas atividades tais como prescrição médica, distribuição, dispensação, transcrição da prescrição e a administração da droga, ou seja, envolve etapas sequenciais e uma equipe multidisciplinar e o erro referente a este procedimento pode ocorrer em qualquer uma dessas etapas [17].

Quanto à revelação da ocorrência de um erro e a comunicaçáo do mesmo, são encontrados como obstáculos: a dificuldade em admitir que errou aliada à possibilidade de sofrer ações éticas e legais, além do medo de envolver outros profissionais [8].

Autores afirmam que os profissionais de saúde não estáo preparados para lidar com o erro, que por sua vez estão associados à vergonha, medo ou puniçóes. Afirmam ainda que isso ocorre em decorrência da própria formação profissional, assim acabam notificando algum erro cometido apenas quando o paciente sofre alguma consequência grave, o que pode ser justificado pelo medo de sofrer puniçôes, como advertência ou até mesmo demissões [9].

Desta forma pode-se considerar que a ocorrência de um erro no processo de administração de um fármaco constitui um problema multidisciplinar. Portanto requer sensibilidade de todos os profissionais envolvidos com o objetivo comum de planejar metas a serem fixadas a curto, médio e longo prazo a fim de sanar, prevenir ou pelo menos reduzir a ocorrência de erros durante esse processo [13].

\section{Causas dos erros de medicaçáo e/ou fatores de riscos}

A ocorrência de erros não deve ser julgada apenas como uma falha humana. É importante que se investiguem as suas causas na tentativa de saná-las, tendo sempre como objetivo principal a adequada assistência à saúde prestada a nosso cliente.

As causas dos erros, conforme citados na literatura, podem estar relacionadas ao sistema de medicaçáo, que engloba desde o momento da prescrição até a administraçáo propriamente dita [16]. 
Autores apontam que é comum nos depararmos com prescriçóes de medicamentos para o cliente pediátrico que não são licenciadas ou de uso não padronizado para crianças. Esta infelizmente constitui uma realidade que não é apenas do Brasil. E isso ocorre devido à "carência de apresentaçóes farmacológicas de uso mais flexível e prevalência elevada de medicamentos comercializados sem informaçóes de doses para crianças" [11].

Acredita-se que a prescrição manual contribua de forma significativa para o surgimento de erros de medicação. A letra ilegível do profissional médico, comum em nosso cotidiano, gera dificuldades como a incompreensão da prescrição, favorecendo a ocorrência de erros em todas as etapas do processo de administraçáo de medicamentos [13].

Um estudo realizado em um hospital geral universitário mostrou que $20 \%$ dos 45 erros encontrados na prescrição e consequentemente na administraçáo de medicamentos, estáo relacionados a problemas de compreensão da letra do médico, que correspondem à má grafia médica na prescrição manual [12].

Autores afirmam ainda que alguns medicamentos náo possuem licenciamento para uso em crianças, em outros países, no entanto são utilizados para esses clientes como é o caso do Brasil. São eles: flumazenil; fentanila; transdérmico; formoterol, entre outros [11].

Vários fatores são capazes de contribuir de forma significativa para o aparecimento de erros relacionados à administraçáo de medicamentos tais como a prática profissional; procedimentos e sistemas, que por sua vez incluem os produtos utilizados para o cuidado; prescrição médica e comunicação da mesma; rótulo do produto e ou embalagem; e divergências de nomenclatura (vários nomes para um mesmo produto); a composiçáo; a administração; a educação dos profissionais e dos pacientes; a supervisão e o uso [15].

A listagem nacional de medicamentos problema em pediatria (MPP) inclui grupos terapêuticos utilizados em grande escala em crianças, tais como antimicrobianos, anticonvulsivantes e antiasmáticos [11].

Um trabalho realizado, no ano de 2007, mostrou que erros podem estar relacionados à falta de atenção, sobrecarga de serviço, estresse, cansaço, falta de funcionários e a letra ilegível dos médicos, no entanto não podemos descartar que as causas também podem estar associadas a falhas no sistema de prevenção de erros [14].
Outros autores referem, ainda, à falta de conhecimento, más condições ambientais, materiais inadequados, além de problemas pessoais que podem levar os profissionais a distraçóes, como, por exemplo, a falta de atenção, deficiência da formação acadêmica, lapsos de memória, inexperiência, desatualização quanto aos avanços tecnológicos e científicos e ainda negligência do profissional, além de negligência e desvio de conduta que contribuem para a ocorrência dos erros $[16,12]$.

Além de fatores individuais, alguns fatores organizacionais presentes nas instituições de saúde também são capazes de gerar erros no processo de administração de medicamentos, como, por exemplo, o treinamento inadequado da equipe; a baixa percepçáo da importância da prescriçáo, a hierarquia presente na equipe médica e a ausência da autoconsciência dos erros [12]. Considera-se, também, que falhas no sistema aparecem como causas importantes de erros de administração de medicamentos. Entre elas podemos citar a iluminaçáo inadequada; as interrupções frequentes; a falta de treinamento; os níveis extremos de barulhos; além de políticas e procedimentos ineficientes, ou mesmo, problemas com os produtos utilizados para administração ou na própria medicaçáo do paciente. Os autores acrescentam a falta de interesse e a pressa como razóes para a ocorrência de erros de medicação [12].

Segundo a literatura pesquisada, as formulações farmacológicas sólidas aparecem como a maioria dos medicamentos com posologia inadequada para crianças. É comum vermos em nosso cotidiano a divisão do comprimido, o que diz respeito ao fracionamento, trituração e diluição dos comprimidos, o que também é característica de falhas no sistema de medicação e não apenas do profissional [11].

A diluição dos medicamentos de forma incorreta contribui de forma significativa para a ocorrência de erros de medicação, uma vez que a diluição do fármaco de maneira inadequada pode provocar falha na terapêutica, e agravos importantes da infecção (no caso de antibióticos) ou quadros de intoxicação [17].

Os erros mais comuns na etapa de dispensação de fármacos, conforme a literatura envolvem doses ou formas incorretas, que podem estar relacionadas com problemas com o ambiente de trabalho [12].

Um estudo realizado em três unidades pediátricas de um hospital universitário em São Paulo mostrou que 40 doses de medicamentos $(2,4 \%)$ das prescritas pela equipe médica deixaram de ser reali- 
zadas por falta da droga na farmácia da instituição [15]. Isso caracteriza um erro de medicação gerado pela falha no sistema da instituição, com provável perda da eficácia da terapêutica escolhida.

Para alguns autores a padronizaçáo dos horários para administraçáo de medicamentos pela equipe de enfermagem, em conformidade com os horários de dispensação de fármacos pelas farmácias hospitalares, favorece o aparecimento de um erro comum de medicação: a interação medicamentosa [13]. É importante lembrar que as interações medicamentosas podem ocorrer no organismo e agem interferindo nos processos de farmacodinâmica dos fármacos, ou seja, prejudicando a absorção, distribuição e eliminação dos medicamentos, além de serem responsáveis pela resposta do paciente ao tratamento medicamentoso [13].

Os autores pesquisados consideram que os enfermeiros mais experientes cometem erros relacionados à medicação com maior frequência que os novatos, pois se sentem convencidos de que seu julgamento e decisão são sempre corretos quando relacionados ao procedimento, mesmo que por vezes estejam errados [9]. É provável que os motivos pelos quais se cometam falhas individuais durante a administração de medicamentos se relacionem à falta de tempo aliada ao excesso de trabalho [12].

A identificação incorreta ou incompleta do paciente internado inviabiliza a utilização dos cinco passos certos da administraçáo de medicamentos, além de contribuir como um importante fator de risco para o erro de medicação [13]. A falha na implementação dos cinco certos e a falha no planejamento do aprazamento da prescriçáo médica acarreta incompatibilidade entre os medicamentos administrados, o que também contribui para o aparecimento dos erros de medicação [15].

Portanto, o despreparo da equipe de enfermagem com relação às técnicas de administração de fármacos e a falta de conhecimento quanto à importância desse procedimento no cuidado do paciente leva a erros de cálculos, de preparo e de administração de medicamentos [15]. No entanto dificilmente o erro ocorre apenas por falhas do profissional, pois deve também ser mais considerado como um erro do sistema que do próprio profissional executante do processo [15].

Não existe no Brasil uma regulação específica para o registro e o uso de medicamentos em crianças. O que faz com que o país permaneça carente de pesquisas e regulaçáo de fármacos para a clínica pediátrica [11].

\section{Prevençáo de erros de administração de medica- mentos em pediatria}

A literatura pesquisada destaca que os erros de medicação em crianças estão entre os agravos mais graves e comuns que esta clientela pode sofrer durante o período de internaçáo. Assim, sistemas de prevenção devem ser desenvolvidos com o objetivo de minimizar erros e alcançar uma assistência de qualidade a esses clientes [10].

O erro faz parte da natureza humana, no entanto, este fato pode ser agravado, quando as práticas, os procedimentos, os protocolos, as rotinas, as técnicas e os equipamentos utilizados pelos trabalhadores são inadequados, complexos e por si só inseguros [15].

O enfermeiro também é responsável pelo treinamento e orientação de sua equipe, quanto ao procedimento de administração de medicamentos, em todas as suas etapas, portanto deve estar sempre informado e atualizado quanto às questóes relativas aos efeitos dos fármacos e controle da resposta do paciente [17].

As instituições de saúde devem ter como meta uma visão ampla do complexo sistema de medicaçáo, o que possibilita aos profissionais de enfermagem uma oportunidade de analisar e intervir nesse sistema de forma que garanta ao paciente uma assistência de enfermagem responsável e segura [16].

Os autores sugerem como medidas de prevenção de erros de medicação: treinamentos periódicos de todas as fases do sistema de medicação para todos os profissionais que estáo envolvidos no processo. $\mathrm{O}$ treinamento deve abordar todas as etapas que vão desde a prescrição até a administração da droga propriamente dita [13]. É de grande importância que dúvidas sejam questionadas e sanadas antes da realização da administração de medicamentos e não apenas após a ocorrência dos erros e isso compreende um papel da supervisão da enfermagem [16].

De acordo com a literatura pesquisada o sistema de medicação é composto por seis processos fundamentais: a padronização do medicamento; a prescrição do medicamento; a revisão e validação da prescrição; a separação e distribuição do medicamento; o preparo e administração do medicamento; o monitoramento da ação ou reação do cliente assistido em relação ao medicamento administrado [15].

Para que se possa implementar um sistema de terapia medicamentosa segura ao paciente é necessário que os enfermeiros conheçam a maneira correta de preparo e de administraçáo de fármacos 
que, a partir da prescriçáo médica, possam executar o aprazamento da administração dos medicamentos, prescrever cuidados coerentes para a administração segura e eficaz dos fármacos, bem como monitorar açóes em casos de efeitos adversos. De forma que as anotaçóes de enfermagem registrem de maneira eficaz e fidedigna as respostas do paciente a terapêutica escolhida [16]. Os autores destacam, ainda, a importância de o enfermeiro conhecer as responsabilidades éticas e legais que rodeiam a execução do procedimento de administraçáo da terapia medicamentosa, o que para eles, promovem a segurança do paciente ao realizarem cuidados de forma competente e de maneira adequada às necessidades do paciente e às características da terapia prescrita [16]. "A fim de prevenir erros de medicação, devem ser implementados sistemas e métodos de trabalho que considerem a segurança do paciente" [16]. Assim, a literatura sugere a instituição de uma equipe multidisciplinar responsável pela criação de estratégias que visem à segurança do paciente na prevençáo de eventos adversos relacionados aos erros de medicação [13].

A implementação de um sistema de notificação de erros, como um meio de detectar erros e eventos adversos, também faz parte dessa estratégia de segurança. Este sistema permite relatar de forma detalhada as circunstâncias que envolvem os eventos relacionados aos erros pela visão dos próprios envolvidos [8]. No entanto esse serviço não deve visar somente à punição do funcionário errante e sim a descoberta das principais dificuldades da equipe, de forma com que o erro contribua para a criação de estratégias de ensino e aprendizagem, buscando a diminuição dos erros de medicação [16]. As notificaçôes dos erros são fontes de informaçóes, que permitem identificar, os tipos, causas e fatores que predispóem o aparecimento dos erros de medicação, além de identificar situaçóes que requerem mudanças na estrutura e processos envolvidos na ocorrência dos respectivos erros [8].

O gerenciamento de risco, a avaliação dos eventos, a análise e a divulgaçáo de informações relacionadas aos erros são importantes passos para se alcançar uma assistência de qualidade ao cliente pediátrico [10].

Outra sugestáo evidenciada pela literatura seria a criação de um manual de normas e técnicas de administraçáo de medicamentos que contenham, além dos procedimentos para a administração dos fármacos, informaçôes com relação às interações medicamentosas; estabilidades dos medicamentos; reaçóes adversas e medidas a serem tomadas em casos de reaçóes adversas. $\mathrm{O}$ mesmo deveria estar disponível para todos os profissionais envolvidos no sistema de medicação e em todas as salas de preparo [13].

"A implementação da prescrição eletrônica é uma forma de modernizar, simplificar e tornar o sistema de medicaçáo mais seguro". O uso da prescrição eletrônica é capaz de eliminar os problemas referentes à ilegibilidade das prescriçôes e consequentemente reduzir os erros relacionados às prescriçóes ilegíveis tornando as fases sequentes do processo de administração dos fármacos mais seguras [16].

Outra sugestão da literatura pesquisada para a prevenção de erros relacionados à administraçáo de medicamentos, é o uso de bombas de infusão inteligentes que consistem em equipamentos eletrônicos de infusão de medicamentos, principalmente os de via intravenosa, capazes de aumentar a segurança do paciente, pois simplifica o procedimento de administraçáo de medicamentos, fornecendo um sistema para checagem e balanço padronizados, o que contribui para aumentar a eficiência da enfermagem. Caracteriza-se como um dos principais sistemas de auxílio à equipe de enfermagem, capaz de promover a segurança do paciente à beira do leito [10].

A padronização das nomenclaturas dos medicamentos (genérico; princípio ativo ou comercial), assim como a forma da dose sem uso de decimais são sugestôes encontradas na literatura pesquisada. Além de treinamentos de todos os médicos em relação a cuidados com prescriçóes de medicamentos; implantação da prescrição eletrônica e utilização do código de barras na administração de medicamentos [13].

Segundo Freitas et al. [9], existem três estratégias capazes de minimizar erros durante o preparo e a administração dos medicamentos. São elas: melhora na comunicação, educação contínua dos profissionais e cumprimento de políticas e procedimentos referentes ao preparo e à administração de medicamentos.

Com o intuito de prevenir erros de administração de medicação, a literatura sugere a utilização da regra dos cinco certos pelos profissionais de enfermagem: paciente certo; droga certa; dose certa; via certa e hora certa. Inclui ainda a educação e a documentação certa, como complemento dessa regra [15]. A literatura recomenda, também, aos profissionais de enfermagem, durante o preparo e administração dos medicamentos, que sempre se lembrem de ler três vezes o rótulo dos medicamentos; esclareçam 
dúvidas antes do seu preparo; identifiquem o medicamento preparado com nome do medicamento; via a ser ministrada, além de certificar-se de que o medicamento a ser administrado não foi suspenso na prescrição médica e possíveis preparos para realização de exames e jejum estabelecido. Sugere também o uso de pulseiras de identificação do paciente, assim como a identificação do leito [17].

É importante incluir nas anotaçôes de enfermagem o planejamento do processo de administração de medicamentos, com o objetivo de prevenir erros de medicamentos e efeitos adversos da medicação. Dessa forma, faz-se necessária a padronização de nomenclaturas; símbolos e métodos de anotaçóes do procedimento de administração de medicamentos em toda a instituiçáo de saúde. Além disso, a dupla checagem de medicação, que se refere à medida que duas pessoas estão envolvidas na execução da atividade de administração da terapêutica de um mesmo paciente [14].

Para que se obtenha um sistema de medicação seguro, é indispensável a existência de recursos humanos em quantidade suficiente para não provocar sobrecarga de trabalho ao profissional de enfermagem, além de uma planta física adequada; recursos financeiros; equipamentos e tecnologia apropriada e um trabalho transdisciplinar que compartilhe os conhecimentos de cada profissional envolvido com o propósito de alcançar resultados mais efetivos na prevenção da ocorrência de erros no processo de administração de medicamentos [14].

Outros autores sugerem a implementação de uma visão sistêmica de prevenção e análise dos erros na medicação. Indicam como solução o aprendizado com os erros, não por meio de análises individuais e sim, redesenhando o sistema, a fim de reduzir a presença dos mesmos, estimulando uma cultura de segurança, de maneira a permitir uma contínua possibilidade de gerenciar os riscos [15].

Em um estudo os profissionais de enfermagem demonstraram acreditar que a reciclagem e treinamento do profissional, assim como prestar mais atenção são fatores que podem contribuir para modificar e até mesmo diminuir a ocorrência de erros [9].

A literatura pesquisada ressalta que sempre haverá necessidade de se manipular os medicamentos em farmácias hospitalares antes de sua dispensação, para isso sugerem que a instituição invista em infraestrutura de laboratório e qualificação técnica dos profissionais envolvidos, incluindo informação e educação dos prescritores, de conhecimentos básicos relacionados à farmacotécnica e cálculos de diluição da dose de fármacos, o que contribuiria na difícil tarefa de adaptar as formulaçóes existentes adequando-as ao cliente pediátrico [11].

A prevenção de erros de administração de medicamentos requer um exercício de paciência, colaboração, perseverança e integração dos profissionais envolvidos nesse processo. Ressalta que para que se garanta uma prática clínica adequada, faz-se necessário o desenvolvimento de uma cultura na qual a equipe e os gestores das instituiçóes de saúde estejam envolvidos em um mesmo objetivo: a segurança do paciente [10].

\section{Conclusão}

Diante do exposto acima, conclui-se que os erros de administração de medicação parecem comuns em nosso meio e se relacionam não apenas ao profissional que executa o procedimento, mas a um complexo sistema, que sem dúvidas ainda é muito falho.

Por fim ressalta-se que os clientes pediátricos ainda permanecem "órfãos” de terapia medicamentosa e a carência de uma legislaçáo que regulamente a realização de pesquisas e desenvolvimento de medicaçôes próprias para estes clientes permanece como um agravante para a ocorrência de erros na administração de medicaçóes nessa população. Desta forma, a criação de legislação específica para este fim seria, sem dúvidas, um grande marco no cuidado e atenção à saúde dessa clientela.

É importante que novas pesquisas sejam realizadas, principalmente em campo, para que as instituiçóes de saúde possam identificar os erros particulares de seu próprio sistema e, então, seja capaz de elaborar medidas próprias para minimizá-los de acordo com sua realidade particular, garantindo assim a esses clientes uma assistência livre de danos.

\section{Referências}

1. Frias AE, Fortes JI. Noçôes de farmacologia. In: Kawamoto E, Fortes JI. Fundamentos de enfermagem edição revista e ampliada. São Paulo: EPU; 1997. p.107-168.

2. Alves AMA, Almeida BA, Esteves D, Viana DL, et al. Enfermagem em pediatria. In: Figueiredo NMA, Viana DL, Machado WCA. Tratado prático de enfermagem. São Caetano do Sul: Yendis; 2008.p. 259-351.

3. Brasil. Agência Nacional de Vigilância Sanitária; Gerência de fármaco vigilância. Informe sobre erro de 
medicação. [citado 2011 Abr 6]. Disponível em URL: http://www.crfsc.org.br

4. Bricks LF. Uso judicioso de medicamentos em crianças. J Pediatr 2003;79(Supl1): S107-S114.

5. Bogdan R, Biklen S. Investigação qualitativa em educação. Porto: Porto; 1994.

6. Mayring P. Introdução à pesquisa social qualitativa. Weinheim: Beltz; 2002.

7. Hondem PC, Matioli CP, Nascimento MAL. Metodologia: interpretando autores. In: Figueiredo NMA. Método e metodologia na pesquisa científica. São Caetano do Sul: Yendis; 2008.

8. Belena ASC, Pertelini MAS, Pedreira MLG. Revelaçáo da ocorrência de erro de medicação em unidade de cuidados intensivos pediátricos. Rev Ter Intensiva 2010;22(3):257-63.

9. Freitas DF, Oda JY. Avaliação dos fatores de risco relacionados às falhas durante a administração de medicamentos. Arq Ciênc Saúde Unipar 2008;12(3):231-7.

10. Pedreira MLG, Pertelini MAS, Harada MJCS. Tecnologia da informação e prevenção de erros de medicação em pediatria: prescrição informatizada, código de barras e bombas de infusão inteligentes. Rev Soc Bras Enferm 2005;5 (1):35-61.
11. Costa PQ, Rey LC, Coelho HLL. Carência de preparaçóes medicamentosas para uso em crianças no Brasil. J Pediatr 2009;85(3):229-35.

12. Silva AEB, Cassiani SHB. Erros de medicação em hospital universitário: tipo, causas, sugestóes e providências. Rev Bras Enferm 2004;57(6):671-4.

13. Oliveira CR, Camargo AEB, Cassiani SHB. Estratégias para prevenção de erros na medicação no setor de emergência. Rev Bras Enferm 2005;58(4):339-404.

14. Yamanaka TI, Pereira DG, Pedreira MLG, Pertelini MA. Redesenho das atividades de enfermagem para redução de erros de medicação em pediatria. Rev Bras Enferm 2007;60(2):190-6.

15. Melo LR, Pedreira MLG. Erros de medicação em pediatria: análise da documentação de enfermagem no prontuário do paciente. Rev Bras Enferm 2005;58(2):180-85.

16. Silva BK, Silva JS, Gobbo AFF, Miasso AI. Erros de medicação: condutas e propostas de prevenção na perspectiva da equipe de enfermagem. Revista Eletrônica de Enfermagem 2007;9(03):712-23.

17. Bueno A, Suyenaga ES. Avaliaçáo do conhecimento da equipe de enfermagem em relaçáo à diluição de antibióticos utilizados no tratamento de pneumonia aguda em pacientes pediátricos. Enfermagem Brasil 2008;7(3):130-3. 